\title{
Arts, Virtue and Character: Perspectives from Philosophy and Psychology
}

\section{Ogunyemi Omowumi}

Institute of humanities, Pan-Atlantic University, Lagos.

\begin{abstract}
:
In today's world, the tendency to live constantly connected to a virtual digital space makes it difficult to have an ambiance that fosters paused reflections. Often times, one needs to make a conscious effort to stop and think if one recognises the importance of reflections for making the deliberated choices needed for self-development. For many people, a break from the frenzy of activities is facilitated by arts, such as narratives and music. Interestingly, more than just means of entertainment, the arts can be important catalysts for learning processes. Ancient philosophers affirmed that music is helpful in education to virtue as it tempers the emotions of a child to raise it towards the good. However, such high regards for art and music in character formation is often forgotten today.From the perspective of contemporary narrative philosophy, each action or choice which builds up into the habit is best understood as part of a continuous narrative. One understands the self better when considering it as the protagonist of a narrative moving from a beginning towards an end, guided by chosen goals which are good for the acting subject. Additionally contemporary psychologists acknowledge the role of the arts in character formation. This conceptual paper brings together ideas from psychology and philosophy in order to explore the role of some forms of art in character development. The appreciation of the on-going construction of the plot of one's life-story guided by the intrinsic goods that promote human flourishing (including aesthetic experiences), may serve as a foundation for understanding the importance of coherence and unity of life for building character.
\end{abstract}

Keywords: narratives, music, character development, self-understanding, psychology, philosophy.

\section{Introduction}

In today's world, the ease of having paused rational reflections seems to decrease as the tendency to live continuously connected to a virtual digital space increases. Often, one needs to make a conscious effort to stop and think if one recognises the importance of paused intellectual reflections for making deliberated choices needed for self-development. Indeed, the desire to direct one's life purposefully towards identified goods requires a deep self-understanding and an understanding of those goods. For many people, such a break from the frenzy of activities is facilitated by listening to music or learning to play a musical instrument. Many fields of enquiry point to the role of music in calming one's nerves or as a source of relaxation and as such a preparation for other intense activity requiring other skills. Philosophy and psychology are only two of these. This attribute of music in preparing the individual for other tasks has been observed along the ages.

Ancient philosophers affirm that music tempers the soul, calms our troubles and gives rest. Music calms the passions making their subject more open to the influence of reason. Such an influence facilitates conscious character formation. In fact, Plato affirmed that music is helpful in education to virtue as it tempers the emotions of a child to raise it towards the good. However, such high regards for art and music in character formation is often forgotten today. A re-awakening of the sensibility to the arts, which was central to holistic education in the past may be beneficial to contemporary life.

While examining the effect of music on our lives we may ask: How can music contribute to wellbeing of the individual? Can music help students to improve their study habits and increase their capacity reinforcement learned habits? Could classical music or natural sounds, or the appreciation of narratives be antidotes for bombardments from social media or a means to facilitate the peace of mind that one needs for study, for calmness, or for the serenity that is required for reasoning and making sound judgements? Could the aesthetic experience contribute to the psychological preparations for learning as it rests the mind? One may also ask for the role of other narrativity in self-understanding and development. Can one see the 
different experiences in life as part of a coherent narrative? Can meaning making, even with the temporal dispersion of one's actions and the complexity and diversity of daily activities, be enhanced by a narrative self-understanding?

This paper explores some ways in which some arts aid character formation and the acquisition of virtues. Through the lens of narrative philosophy, it shows the nexus between musical appreciation and the acquisition of virtues that comes when musical training is connected to various aspects of human life. While this is a philosophical paper, it uses insights from contemporary psychology to reinforce the discussion of the topic.

\section{Ancient Wisdom}

The explanation of the role of the arts including music and drama in preparing the soul for ordered choices and intentional orientation towards the good is a topic in ancient philosophy. Aristotle's description of art, especially tragedies, and the role of our imitation of nature in artistic representations compares human lives within classic literature with philosophy ${ }^{1}$ (Aristotle). Narrative philosophy may be linked to the lives of characters in dramas. For Aristotle, Poetics (as a broad term corresponding to what is contemporarily known as arts, drama, narratives, poems with its rhythm and musical structure etc.) is natural to humans and indeed distinguishes us from animals (Kenny \& Amadio, 2018). As will be seen further on, the presence of narrative structure in human life has been developed in contemporary philosophy. Alasdair Macintyre is perhaps the most influential contemporary theorist of narrative philosophy developed within an Aristotelian-Thomistic framework and this paper will refer to his work.

Plato is often quoted when talking specifically about music in human life. Even though many quotes about music which were attributed to Plato are not traceable to him, his well-known book which includes a discussion on the character of people in the society, Republic, emphasizes the role of music in the development of the society.

Music calms the passions and thus can make the listening subject more open to the influence of reason. Such an influence would facilitate conscious character formation. If the passions are made more open to the influence of reason, the capacity to identify one's true good and to follow it can be enhanced. One can infer that the possibility of knowing which actions are truly good, in as much as it is a task of discernment attributed to the intellect, may be helped by the calming effect of music. When such good actions are chosen and repeated by the subject, they develop habits which move them towards their ultimate end. Those good habits are virtues. In fact, Plato affirmed that music is helpful in education to virtue as it tempers the emotions of a child to raise it towards the good.

Tempering the soul is needed today, as many young minds are steeped in habits which make it difficult for them to be open to change or to understand abstract thought and systematic logical analysis. Even more difficult for today's youth is the discernment of helpful principles as many common expressions and slogans for their daily activity are often general notions picked up while overhearing erroneous and baseless arguments among others around them, and not conclusions made after calm reflections. If music tempers the soul, as Plato affirms, one may infer that it could help preparing one for deeper reflections on the good for human life and thus facilitate the process of directing oneself towards what one sees as good.

In order to maintain activity leading to acquiring internal goods such as virtues and character strengths, individuals may need to reflect on its value understand its implications for a good life and repeatedly make choices in conformity with their life's goals. Each choice can then become a step towards achieving one's objectives. Music may contribute to mental preparation and thus prepare the subject for making pondered decisions.

The many choices which one makes, with regard to learning music or appreciating its beauty, are spread out over a period. Developing an ear for music or increasing one's capacity to appreciate beauty requires repeated efforts at improving one's of grasp of the richness of melody and rhythm. Like other actions, the learning process is affected by temporal condition and the spread of various actions over time. Within the process of self-development, there is often the dilemma of how to understand the integration of temporally dispersed choices and actions into the framework of one's efforts to reach a specific goal (Ogunyemi, 2017). Having to carry out activity in sequences (as opposed to a simultaneous eternity) makes it challenging to purposefully unite them. The human being's temporal experience brings with it the challenges in self-

\footnotetext{
${ }_{1}^{1}$ Philosophers who are well known for writings related to the narrative self include, Alasdair Maclntyre, Paul Ricoeur, Charles Taylor, and David Carr. Many of these authors, as well as Dan P. McAdams (a contemporary psychologist carrying out ongoing research on the narrative study of human lives) base their analysis of narratives on the Aristotelian concept of narratives and arts especially noticeable in the book Poetics.
} 
understanding and meaning making over time. Contemporary philosophy identifies Narrative self-understanding as a tool for the development of virtues in a sustainable way.

\section{Contemporary philosophy}

In Maclntyre's works and especially in After Virtue, he presents the human being as the protagonist of a personal narrative which is intertwined with narratives of other people in society and also with the history and tradition of that community. The narrative approach to understanding the human being in relation to his end gives a global perspective of humans which helps to deepen our understanding of ourselves.

MacIntyre's views on the intelligibility of human action within a narrative are a prominent theme in the book After virtue and Ethics in the Conflicts of Modernity. For Maclntyre, narrativity is a central element in any attempt to understand the meaning of any individual actions. The way in which actions are given meaning within the particular contexts is by their being fitted into stories and narratives which necessarily extend beyond specific action settings to include the whole of the individual's life, the stories of one-on-one relationships within families, society and traditions of thought and enquiry. In its basic sense, a narrative is a meaningful account of actions and their circumstances which are ordered according to a particular intention or set of intentions. Each action, even though situated in a different temporal point from others, within an apparent simple sequence is actually linked to others through a narrative structure inherent in human life.

Human beings, in the process of self-improvement and development, often set specific goals which take them towards bigger goals. This hierarchy of goods in seen both in Aristotelian-Thomistic tradition. The journey towards the greatest good or telos involves many steps which are fuelled by the desire for that ultimate good. In that sense, the telos connects all these varied steps, and narrative self-understanding throws more light on that nexus. One can say that the ultimate end (telos) of the person connects all the individual's actions while he or she weaves his more or less coherent life's narrative around it with each of his individual actions.

The quest for the telos involves many actions and those actions which move one towards that end are good for the acting person while those that move them away from the desirable end are bad for them. Many of these actions will need to be repeated and may become a habit or second nature to the acting person. These repeated good actions forming good habits are the virtues. Virtue here is seen as a stable character disposition and is acquired with time with repeated actions. Acquiring good habits often requires self-control and discipline. According to Maclntyre, "the virtues are precisely those qualities the possession of which will enable an individual to achieve Eudaimonia, and the lack of which frustrate his movement toward the telos." (MacIntyre, 2013, p. 148). Interestingly, these virtues are not limited to only one sphere of life as a virtuous person exhibits the virtues in all aspects of life. The virtues that one strives to acquire in the musical aspects of one's life form part of the life story. Maclntyre taking up the Aristotelian concept of a virtue affirms that a virtue is lived in diverse situations, and "the unity of virtue in someone's life is intelligible only as a characteristic of a unitary life, a life that can be conceived and evaluated as a whole." (Maclntyre, 2013, p. 52). Thus, his concept of selfhood calls for a self whose unity resides in the unity of a narrative which links birth to life to death, as a narrative from beginning to middle to end (Maclntyre, 1990).

Considering the importance of the telos for self-understanding, for the identification and acquisition for virtues, one may then ask: how can one identify the telos for the human being? In relation to that question, Maclntyre speaks about the difference between "man-as-he-happens-to-be" and "man-as-he-could-be-if-he-realised-his-essential-nature". Thus Maclntyre refers to the human being's essential nature as a guide for constructing one's personal narrative. Thus, human nature and the laws inscribed in it forms the coordinates and guides to what a successful personal narrative should be.

The transition from the former state to the latter pre-supposes some metaphysical concepts: potentiality and act, some account of the essence of a human being as a rational animal and above all some account of the human telos (Macintyre, 2013). Maclntyre's approach to ethics, as is often seen within the Aristotelian-Thomistic Tradition, is characteristically teleological, in that it interprets individual actions in terms of their ultimate end (telos); for him, that which is the good thing to do is that which is virtuous, and that which is virtuous is nothing else than that which will effectively lead to human fulfilment, specifically Eudaimonia. ${ }^{1}$ In all, virtues are built with different individual actions all linked together by the telos

\footnotetext{
${ }^{1}$ Maclntyre's interest in Eudaimonia is Aristotelian. Aristotle regards human life as consisting of aims and ends and describes the end at which all men ought to aim. He describes this end as Eudaimonia and this word is usually translated as 'happiness'. Interpreters of
} 
and best understood through the narrative structure inherent in life. One may infer that the preparation of the mind for understanding and calm reflection, a role ascribed to music could foster a deeper understanding of the essence of reality, including that one's own personhood and even one's own telos under appropriate circumstances. Thus the aesthetic experience and appreciation of beauty are part of the thread that each protagonist of a personal myth weaves together with other events.

\section{Insights from Positive Psychology}

Along the centuries, from its inception as an empirical field of enquiry separate from philosophy, psychology studied the human mind with emphasis on disease states. Recently, psychologists lay great emphasis on the psychology of normal individuals and propose theories of normal psychology, happiness and well-being. For example, Martin Seligman ${ }^{1}$ made a strategic shift from studying pathology to health, resilience, and high performance, creating a more positive psychology. These points of psychology can be interpreted in the light of the philosophical quest for understanding human fulfilment. The concept of narrative or of the development of personal identity through constructing life stories is one such recently explored topic which is of notable importance in contemporary psychology. An increasing number of psychologists argue that people give meaning to their lives by constructing and internalizing self-defining stories (Josselson, Lieblich, \& McAdams, 2006).

Interestingly, contemporary psychologists acknowledge the importance of arts for understanding human happiness and character strengths that lead to happiness and wellbeing. Positive psychologists, Peterson and Seligman, list the "appreciation of wonder" as one of the signature strengths that lead to human satisfaction in life. They describe appreciation of beauty and excellence [awe, wonder, elevation] as noticing and appreciating beauty, excellence, and/or skilled performance in all domains of life, from nature to art to mathematics to science to everyday experience. Such appreciation, although it covers many fields, would apply to music and narratives as common forms of art through which humans can see beauty and excellence in everyday life. One may ask: Could this "appreciation for wonder" be a counterpart of the aesthetic experience which philosophers describe as an intrinsic good, a part of human fulfilment? Appreciation of music would then be an element that contributes to fulfilment. Music can be a catalyst for self-understanding. It can calm the passions and thus can foster development of the human mind.

From another perspective within positive psychology, Csikszentmihalyi while describing flow, the psychology of optimal experiences, relies on the example of satisfaction and engagement that people can attain with musical activities. His description of flow presents this psychological state as the closest to happiness which individuals feel. Attaining flow is a pointer towards satisfaction with life and music is one of the common examples of activities that can lead to flow (Csikszentmihalyi, 1991).

\section{Music and Character}

We will approach the discussion on the possible contribution of music to character formation from two perspectives. First, the role of music as a preparatory activity for noble activities by the soul, secondly music as a booster for cognitive capacities and thirdly the connections between the virtues acquired in music and the other aspects of personal development and character building.

When it comes to discussing the effects of musical training on personality development, one sees that a training in music requires discipline. The professional musician needs to develop some habits that are essential for dexterity and having high standards in their profession. Such training usually requires many hours of dedicated practice. In striving to achieve these habits, the musician can also inadvertently gain self-discipline and self-mastery among other virtues. If one were to consider the unity of the human being, one can infer that these acquired virtues are not necessarily applicable to musical performances but can be linked to other aspects of life.

Aristotle generally find this translation unsatisfactory as happiness in common language describes a feeling whereas Aristotle's

Eudaimonia means a certain kind of activity which is in accord with virtue.

${ }^{1}$ Commonly known as the founder of Positive Psychology, Martin E. P. Seligman is a leading authority in the fields of Positive Psychology, resilience, learned helplessness, depression, optimism and pessimism. He is also a recognized authority on interventions that prevent depression, build character strengths and promote well-being. 
A specific example of a development in one's character is the ability to be constant in practising the playing of an instrument if one is to master that art. Being part of a choir and training one's voice may help one learn to persevere in the practice of actions which may be arduous and, in themselves, amount to little but which are essential for the mastery of one's art and excellence in performances.

An application of narrative philosophy to this example makes us infer that the self-mastery control necessary for developing in the chosen art could be applied to other areas of one's life which require such habits. Such habits are formed in one subject whose actions are interrelated through a continuity that takes the form of a narrative being lived. Thus, those temporally dispersed actions come together with the plot giving rise to a meaningful narrative.

Music is regarded as a booster for cognitive capacities. Scholars affirm that music education facilitates the human capacity for other intellectual activities, such as academic ability noticeable in the improved performances in cognitive tasks in students undergoing music education. Costa-Giomi (2004) examines the evidence to support the assertion that attending music lessons can produce significant increases in other cognitive areas. Many times music education will focus on developing skills at reading and writing music of different types, training the ears in the aesthetic appreciation of sounds by playing instruments. However, such training develops the cognitive areas and thus may improve the application of one's intellectual capacity to other cognitive tasks. The investigation of the effect of musical training on the application of one's intellectual capacities on tasks other than music could be an interesting topic for empirical evaluation. Scientists have established a positive correlation between language capacity and musical education. One could investigate further on the possibilities of association between other cognitive functions that are related to recognizing values, and music education.

There are studies which show significant correlation between music education and improved cognitive abilities related to academic performances. Even when the mechanisms of the correlation between music education and its impact of other aspects of cognitive functions are not clear, there is a positive relationship between learning music and academic achievement (dos Santos-Luiz, Mónico, Almeida, \& Coimbra, 2016). The effects of music on cognitive capacities of students have been studied by other scientists and educators with similar results. In a study comprised of primary school children, the test scores on inhibition, planning and verbal intelligence increased significantly in the two music groups over time as compared to the visual art and no arts control groups (Jaschke, Honing, \& Scherder, 2018). In fact, "after controlling for intelligence, socioeconomic status and motivation, music training is positively associated with academic achievement" (dos Santos-Luiz et al., 2016).

Considering a narrative integration of different aspects of life into one purposeful unit, a virtue acquired in one domain can be practiced in various different situations that call for the practice of that virtue. The implications of such positive impact of music on learning and cognitive functions could have consequences that go beyond education in musical skills. Given the proven benefits of music to the development of cognitive capacities in adolescents, musical training could be a step towards preparing the mind for learning truths. These truths are not limited to those for practical everyday living or scientific discoveries; they may extend to capturing the essence of reality. An understanding of the nature of reality may help one's relationship with it. For example, if one is better equipped to understand the importance of a balanced ecosystem, and one is better able to recognise the effects of responsible care of the environment on ecological balance, it may be easier to accept injunctions or directions aimed at protecting the environment. In fact, such a deep understanding of the features or aspect of nature and the necessity for working for equilibrium among the inhabitants of the same earthly space may already motivate responsible ecological behaviours. The insight produced from this knowledge can fuel a desire for what others will perceive as ethical behaviour, it will, however, stem from a love for nature. That love for nature is sustainable because it will be a rational conclusion from understanding the goods at stake in the quest for ecological balance. In this example, love is taken in the Aristotelian-Thomistic sense as a desire for possessing a known good.

\section{Conclusions}

Music tempers the spirit prepares it for learning-philosophy and music education research. If music improves cognition, it may enhance a knowledge of the good, and facilitate a motivation to direct one's life towards the good. Looking at Maclntyre, man as he is man as he would be if he knew what his true good is, a logical correlation exists between the possibilities of living a good life and knowing what a good life really means. Knowing that which is one's true good (the ultimate good qua human being), increases one's chances of acting according to it. The decision to act according to that known good requires the practice of virtues, and the effort to repeat good acts and form habits is central to character formation. 
The unity of the person and narrative coherence would explain that virtues acquired through music education (enjoyable ones that can lead to flow) are applicable to other aspects of life. They can influence character if the learning subject see the abilities developed in music as a channel to order their natural tendencies to producing goods of the mind and body.

From all the above observations from psychology, philosophy, education in music, etc., one can infer that a training in music, as it forms people in virtues and cognition (and understanding), can aid character formation. However, such a help from music to proper character formation is not automatic as one can acquire bad habits and be tenacious to them. One can be diligent and consistent in doing things that are harmful to the self or to others. Note that, as discussed earlier, one often does these harmful things because one erroneously perceives them to be good. It follows that, for music training to be helpful, it would have to be concomitant with teaching positive values and helping students to harness their natural character traits thus strengthening them and building up their character and personality.

From the perspective of narrative philosophy, each action or choice which builds up into the habit is best understood as part of a continuous narrative. One understands the self better when considering it as the protagonist of a narrative moving from a beginning towards an end, guided by chosen goals which are good for the acting subject. I propose that the appreciation of the on-going construction of the plot of one's life-story guided by the intrinsic goods that promote human flourishing (including aesthetic experiences), may serve as a foundation for understanding the importance of coherence and unity of life for character formation and value education.

From the discussion on the effects of music on character, one sees that music can contribute to wellbeing of the individuals by preparing them for calm reflection and possibly improving their chances of making choices that move them towards what they are able to understand as truly good for them. Music may help students to improve their study habits and other aspects of their character as the virtues associated with musical training may reflect in other aspects of their lives.

Although this is yet to be tested, introducing the aesthetic experience into college education could promote a habit of selfreflection or examination and also help students grow in virtue. It seems that the aesthetic experience contributes to the psychological preparations for learning as it rests the mind. Concomitant education in virtues (for example through activities that stimulate living specific virtues) could potentiate the capacity of education in arts as both music and narrative selfevaluation could facilitate character formation. In addition, the dedication necessary to produce a musical masterpiece could train the mind to have the strength to do what contributes to one's true good even when that good is difficult to attain.

Another possible topic for empirical verification could be the evaluation of classical music or natural sounds as antidotes to agitation and stress which people may get from a frenzied lifestyle and from bombardments from social media or as a means to facilitate the peace of mind that one needs for study, for calmness, or for the serenity that is required for reasoning and making sound judgements. Such empirical evaluation may confirm a positive role of music and narrative arts in character formation.

\section{Bibliography}

[1] Aristotle. (1962). The Nicomachean ethics. (H. Rackham, Trans.) (Repr). Cambridge, MA: Harvard University Press.

[2] Aristotle. (1995). Poetics. (S. Halliwell, Trans.). Cambridge, MA: Harvard University Press.

[3] Csikszentmihalyi, M. (1991). Flow: the psychology of optimal experience. New York: HarperPerennial.

[4] Costa-Giomi, E. (2004). Effects of three years piano instruction on children's academic achievement, school performance and self-esteem. Psychology of Music, 32(2), 139-152.

[5] dos Santos-Luiz, C., Mónico, L. S. M., Almeida, L. S., \& Coimbra, D. (2016). Exploring the long-term associations between adolescents' music training and academic achievement. Musicae Scientiae, 20(4), 512-527.

[6] Jaschke, A. C., Honing, H., \& Scherder, E. J. A. (2018). Longitudinal Analysis of Music Education on Executive Functions in Primary School Children. Frontiers in Neuroscience, 12.

[7] Josselson, R., Lieblich, A., \& McAdams, D. P. (Eds.). (2006). Identity and story: creating self in narrative. Washington, DC: American Psychological Association.

[8] Kenny, A., \& Amadio, A. (2018). Aristotle. In Encyclopædia britannica. Encyclopædia Britannica, inc. Retrieved from https://www.britannica.com/biography/Aristotle

[9] Maclntyre, A. (2013). After Virtue: A Study in Moral Theory (3rd ed.). London: Bloomsbury. 
[10] Maclntyre, A. (1987). Can One Be Unintelligible to Oneself? In C. McKnight \& M. Stchedroff (Eds.), Philosophy in its Variety: Essays in Memory of François Bordet (pp. 23-37). Belfast: Queen's University of Belfast.

[11] MacIntyre, A. (2014). Ends and Endings. American Catholic Philosophical Quarterly, 88(4), 807-821.

[12] Macintyre, A. (1977). Epistemological Crises, Dramatic Narrative and the Philosophy of Science. Monist, 60(4), 453-472.

[13] Maclntyre, A. (2016). Ethics in the Conflicts of Modernity: An Essay on Desire, Practical Reasoning, and Narrative. Cambridge: Cambridge University Press.

[14] Maclntyre, A. (1990). Three rival versions of moral enquiry: encyclopaedia, genealogy, and tradition. London: Duckworth.

[15] McAdams, D. P. (1997). The stories we live by: personal myths and the making of the self. New York: Guilford Press.

[16] McAdams, D. P. (2001). The Psychology of Life Stories. Review of General Psychology, 5(2), 100-122.

[17] McAdams, D. P. (2006a). The redemptive self: stories Americans live by. Oxford: Oxford University Press.

[18] McAdams, D. P. (2006b). The Role of Narratives in Personality Psychology Today. Narrative Enquiry, 16(1), $11-18$.

[19] Ogunyemi, O. (2017). The Unity of Autobiographical Temporality of the Narrative Self in Contemporary Psychology and Neurosciences: A Philosophical Study. Rome: EDUSC.

[20] Thomas Aquinas. (1994). Commentary on Aristotle's Nicomachean Ethics. Notre Dame, IN: Dumb Ox Books. 